JAMP: Jurnal Adminitrasi dan Manajemen Pendidikan

Volume 4 Nomor 2 Juni 2021, Hal : 171 - 177

Tersedia Online di http://journal2.um.ac.id/index.php/jamp/

ISSN 2615-8574 (online)

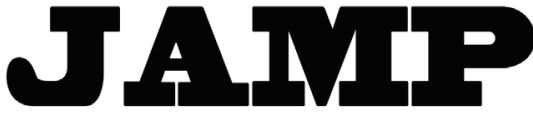

JURNAL ADMINISTRASI DAN MANAJEMEN PENDIDIKAN

\title{
STRATEGI PEMBINAAN PESERTA DIDIK DALAM RANGKA PENGUATAN PENDIDIKAN KARAKTER BERBASIS NILAI PANCASILA DI SEKOLAH DASAR
}

\author{
Maisyaroh $^{1}$ \\ Sri Untari ${ }^{2}$ \\ Tutut Chusniyah ${ }^{3}$ \\ Dedi Prestiadi ${ }^{1}$ \\ Endrik Mas Yulaidi \\ Maulana Amirul Adha ${ }^{1}$ \\ Bagus Rachmad Saputra ${ }^{1}$ \\ Nova Syafira Ariyanti ${ }^{1}$
}

\begin{abstract}
${ }^{1}$ Fakultas Ilmu Pendidikan, Universitas Negeri Malang - Jalan Semarang No. 5 Malang
${ }^{2}$ Fakultas Ilmu Sosial, Universitas Negeri Malang - Jalan Semarang No. 5 Malang

${ }^{3}$ Fakultas Pendidikan Psikologi, Universitas Negeri Malang - Jalan Semarang No. 5 Malang

${ }^{4}$ SD Laboratorium Universitas Negeri Malang Kota Blitar - Jalan Ir. Soekarno No. 1 Kota Blitar

Email: maisyaroh.fip@um.ac.id*
\end{abstract}

\begin{abstract}
The purpose of this study is to describe the strategy of strengthening character education based on Pancasila values through coaching students at the Elementary School Laboratory Universitas Negeri Malang, Blitar City. The research was conducted qualitatively with a case study approach. Data obtained through unstructured interviews, observation and documentation study. Data credibility checks were carried out using triangulation techniques, random member checks and discussion with fellow researchers. The results of this study indicate that the strategy of coaching students in order to strengthen Pancasila valuebased character education is divided into learning and non-learning aspects. The strategy to strengthen character education based on Pancasila values in schools is implemented in accordance with the vision and mission of the school including being adjusted to the characteristics of school learning oriented towards western education patterns by focusing on understanding and using English as the excellence of the school. Combined with eastern customs which are described in the character building activities of students.
\end{abstract}

Keywords: strategy; strengthening character education; pancasila value; elementary school laboratory.

Abstrak: Tujuan penelitian ini yakni mendeskripsikan strategi penguatan pendidikan karakter berbasis nilai pancasila melalui pembinaan peserta didik di SD Laboratorium UM Kota Blitar. Penelitian dilakukan secara kualitatif dengan pendekatan studi kasus. Data diperoleh melalui wawancara tidak terstruktur, observasi dan studi dokumentasi. Pengecekan kredibilitas data dilakukan dengan menggunakan teknik triangulasi, pengecekan anggota secara acak (random member check) dan diskusi teman sesama peneliti. Hasil penelitian ini menunjukkan strategi pembinaan peserta didik dalam rangka penguatan pendidikan karakter berbasis nilai pancasila dibagi ke dalam aspek pembelajaran dan non pembelajaran. Strategi penguatan pendidikan karakter berbasis nilai pancasila di sekolah dilaksanakan sesuai dengan visi dan misi sekolah termasuk disesuaikan dengan ciri khas pembelajaran sekolah yang berkiblat pada pola pendidikan barat dengan berfokus pada pemahaman dan penggunaan Bahasa Inggris sebagai keunggulan sekolah. Dipadukan dengan adat ketimuran yang dijabarkan dalam kegiatan pembinaan karakter peserta didik.

Kata Kunci: strategi; penguatan pendidikan karakter; berbasis pancasila; sekolah laboratorium. 
Degradasi moral atau karakter di tengah masyarakat, menjadi ancaman dan problematika yang harus di selesaikan oleh bangsa indonesia. Degradasi moral yang dimaksud yakni kemerosotan nilai-nilai serta kualitas hidup dan kemerosotan identitas kehidupan bangsa. Degradasi moral yang terjadi pada kalangan peserta didik hari ini sangat memprihatinkan begitu banyak terjadi penyimpangan seperti perkelahian antar peserta didik, perilaku bullying, berkurangnya kepedulian terhadap sesama, dan lainnya. Pendidikan dapat dijadikan alternatif pencegahan dalam perannya menciptakan peserta didik yang berkarakter. Pendidikan sebagai alternatif pencegahan diharapkan bisa meningkatkan mutu peserta didik dalam berbagai aspek yang bisa mereduksi penyebab berbagai problem karakter bangsa.

Penguatan karakter peserta didik harus dirumuskan melalui strategi yang tepat oleh sekolah agar kemungkinan keberhasilan pencapaian tujuan dapat dioptimalkan (Diggs \& Akos, 2016; Fahrilyani et al., 2019). Strategi penguatan pendidikan karakter di sekolah yang direncanakan dan dilaksanakan memiliki pengaruh yang besar bagi terbentuknya karakter peserta didik (Raihani, 2011; Sukadari et al., 2019). Strategi baik yang bersifat pembelajaran di kelas maupun non pembelajaran di kelas yang diterima oleh peserta didik menjadi kebutuhan penting untuk membangun masa depan mereka. Penanaman nilai karakter berbasis pancasila menjadi salah satu karakter yang harus dibentuk (Amir, 2013; Parker \& Raihani, 2011). Pelaksanaan program pendidikan karakter sendiri telah diatur dalam Permendikbud No. 20 Tahun 2018 Tentang Penguatan Pendidikan Karakter Pada Satuan Pendidikan Formal. Dimana dalam Permendikbud tersebut terdapat lima nilai pokok prioritas karakter Pendidikan Penguatan Karakter yang dilaksanakan pada tingkat satuan pendidikan yaitu religius, nasionalis, berintegritas, gotong royong, serta kemandirian.

Ancaman era globalisasi yang semakin masif, jabaran nilai-nilai pendidikan karakter dirasa perlu oleh pemerintah untuk diintegrasikan dengan kegiatan pembelajaran maupun non pembelajaran di sekolah atau madrasah (Dennis \& Harrison, 2020). Kajian teoritis dan praktis dari berbagai penelitian yang telah dilakukan menyimpulkan bahwa penyelenggaraan pendidikan karakter perlu didukung oleh strategi yang tepat (Muassomah et al., 2020; Parker \& Raihani, 2011). Tanpa adanya strategi yang tepat dan akurat, penguatan pendidikan karakter di sekolah tidak dapat berhasil secara optimal (Izfanna \& Hisyam, 2012; Jianfei et al., 2017). Hal ini berkaitan dengan aspek pemahaman kepala sekolah dan guru terdapat nilai-nilai yang terkandung dalam pendidikan karakter yang kemudian dapat diimplementasikan ke dalam program sekolah (Arifin et al., 2018; Juharyanto, et al., 2020).

Penelitian sebelumnya tentang pendidikan karakter diarahkan pada program pembelajaran dan hasil dari penerapan pendidikan karakter terhadap perubahan karakter peserta didik dan hasil belajar peserta didik (Agboola \& Tsai, 2012; Djiwandono, 2016; Hidayati et al., 2014). Penelitian (Iswan \& Bahar, 2018) menekankan pendidikan karakter pada pembentukan karakter peserta didik dalam aktivitas pembelajaran di era revolusi industri 4.0. Oleh karena itu penelitian ini tergolong masih baru karena belum banyak yang menyinggung tentang strategi sekolah dalam rangka penguatan pendidikan karakter yang diambil dari lima nilai dasar Pancasila sebagai wujud karakter bangsa yang hendak dicapai melalui pembinaan peserta didik.

Salah satu sekolah bermutu yang saat ini banyak diminati adalah sekolah dasar laboratorium yang secara umum berada di bawah naungan perguruan tinggi, salah satunya adalah Sekolah Dasar Laboratorium Universitas Negeri Malang (UM). SD Laboratorium UM, memiliki visi yakni terwujudnya sekolah dasar yang unggul dalam pendidikan untuk menghasilkan lulusan yang bertaqwa, cendikia, berkarakter, berbudaya, dan peduli lingkungan dalam kehidupan global. Berdasarkan visi tersebut, SD Laboratorium UM memiliki salah satu misi yakni menyelenggarakan dan mengembangkan pendidikan karakter dan budaya melalui pembiasaan-pembiasaan positif penuh keteladanan guna menghasilkan lulusan yang berkarakter. Terdapat program-program inovatif sekolah guna penguatan karakter anak, sesuai dengan lima nilai dasar Pancasila sebagai wujud karakter bangsa yang hendak dicapai (Ahmad, 2018; Amir, 2013). Penelitian ini berupaya mendeskripsikan strategi pembinaan peserta didik dalam rangka penguatan pendidikan karakter yang diimplementasikan di SD Laboratorium UM. 


\section{METODE}

Penelitian ini didekati secara kualitatif dengan menggunakan rancangan studi kasus. Peneliti memfokuskan secara mendalam tentang strategi sekolah dalam penguatan pendidikankarakter berdasarkan nilai religius, nasionalisme, gotong royong, kemandirian, dan integritas. Pengumpulan data dilakukan melalui wawancara mendalam tidak terstruktur dengan informan kunci yakni kepala sekolah dan sebagai informan tambahan yakni guru, tenaga kependidikan, dan komite sekolah, kemudian didukung dengan observasi non-partisipatif, dan studi dokumentasi yang terkait dengan fokus yang diteliti oleh peneliti. Pengecekan kredibilitas data dilakukan dengan menggunakan teknik triangulasi. Teknik lainnya yang digunakan di dalam mengecek kredibilitas data penelitian ini adalah pengecekan anggota secara acak (random member check) dan diskusi teman sesama peneliti. Pelaksanaan auditabilitas data penelitian ini dijelaskan secara singkat sebagai berikut. Begitu pengumpulan dan penganalisisan data pada situs selesai dilakukan, maka dilakukan pengecekan konsistensi antara rumusan kesimpulan, temuan-temuan sementara, paparan data, dan catatan lapangan. Adapun teknik analisis data yang dilakukan yaitu mulai dari reduksi data, penyajian data, dan penarikan kesimpulan/verifikasi Miles et al. (2014).

\section{HASIL}

Perumusan strategi penguatan program pendidikan karakter dari sisi pembinaan kegiatan peserta didik dilakukan oleh kepala sekolah dengan melibatkan guru, tenaga kependidikan, dan juga komite sekolah. Strategi pembinaan peserta didik ditekankan pada lima nilai karakter yang harus dimiliki oleh peserta didik yakni religius, nasionalisme, gotong royong, kemandirian, dan integritas. Kelima nilai tersebut dalam aktivitas pembinaan peserta didik dilakukan pada aktivitas pembelajaran dan non pembelajaran. Pada aktivitas pembelajaran nilai-nilai karakter tersebut diintegrasikan dalam Rencana Program Pembelajaran (RPP) yang disusun oleh guru. Strategi penguatan pendidikan karakter di sekolah dilaksanakan sesuai dengan visi dan misi sekolah termasuk disesuaikan dengan ciri khas pembelajaran sekolah yang berkiblat pada pola pendidikan barat dengan berfokus pada pemahaman dan penggunaan Bahasa Inggris sebagai keunggulan sekolah. Dipadukan dengan adat ketimuran yang dijabarkan dalam kegiatan pembinaan karakter peserta didik. Sementara pada program non-pembelajaran dilaksanakan pada pembinaan ekstrakurikuler dan juga peringatan-peringatan hari besar keagamaan atau hari nasional.

Pola pendidikan barat yang dimaksud adalah penerapan kurikulum cambridge yang diadopsi dari CIE (Cambridge International Examinations). Strategi yang dirumuskan memegang peranan penting guna memudahkan guru dalam melaksanakan tugasnya. Dalam mengimplementasikan strategi sekolah, guru dalam melaksanakan perencanaan pembelajaran berbasis Cambridge di SD Laboratorium UM Kota Blitar menganalisis Framework yang sudah ditentukan oleh universitas Cambridge sendiri. Cambridge Framework, silabus setiap mata pelajaran, Rencana Pelaksanaan Pembelajaran (RPP), dan bahan ajar merupakan bahan yang disiapkan oleh guru sebelum proses pembelajaran. Framework itu sendiri adalah acuan untuk pembelajaran setiap harinya. Seperti dalam pembuatan silabus. Dalam membuat silabus seorang guru juga harus melihat frameworknya dulu. Kemudian dari framework itulah nanti dipetapetakan sesuai dengan jenjang dan mata pelajarannya. Ada untuk siswa dan untuk guru, yaitu yang disebut teacher resourches. Proses perencanaan pembelajaran di SD Laboratorium UM Kota Blitar, mengintegrasikan antara kurikulum nasional, kurikulum cambridge dan pedoman PPK.

Strategi pembinaan kegiatan peserta didik dijabarkan dalam aktivitas pembelajaran dan nonpembelajaran baik melalui intrakurikuler dan ekstrakurikuler dengan strategi pembiasaan. Program pembelajaran dalam rangka membina peserta didik pada program penguatan karakter antara lain: (1) melatih peserta didik mengerjakan piket kelas, jum'at bersih, kerja kelompok serta diskusi (2) menyanyikan lagu Indonesia Raya serta upacara bendera, (3) pelaksanaan sholat dhuha dan dhuhur berjamaah, pembiasaan berdoa bersama, jum'at amal, kajian kegiatan keagamaan, (4) melatih peserta didik untuk mengerjakan tugas secara mandiri, dan (5) memberikan program pembelajaran yang menunjukkan sikap tanggung jawab dan dapat menyelesaikan pekerjaan tepat waktu.

Aktivitas lain yang sifatnya non-pembelajaran di dalam kelas antara lain: (1) mengikuti lombalomba peringatan hari besar nasional, mengikuti kegiatan seremonial yang dilaksanakan oleh pemerintah 
contohnya Blitar Tempo Dulu, (2) melakukan kegiatan kerja bakti dan tolong menolong di rumah, (3) adanya toilet training bagi kelas bawah, loker mandiri disekolah, (4) kesadaran peserta didik dalam membereskan tempat makan mereka sendiri setelah selesai makan. Pada aktivitas tersebut guru dapat bekerjasama dengan orang tua peserta didik sebagai upaya menginternalisasi nilai-nilai karakter melalui aktivitas siswa dalam kesehariannya.

\section{PEMBAHASAN}

Pendidikan karakter memiliki esensi yang sama dengan pendidikan akhlak dan pendidikan moral (Izfanna \& Hisyam, 2012; Krettenauer, 2020b). Tujuannya yakni menciptakan individu peserta didik, agar dapat menjadi manusia yang baik, warga masyarakat, serta warga negara yang baik (Krettenauer, 2020a). Adapun kriteria manusia yang baik, serta warga negara yang baik bagi suatu masyarakat atau bangsa, secara umum adalah nilai-nilai sosial tertentu, yang dipengaruhi oleh budaya masyarakat dan bangsanya (Amir, 2013; Sukadari et al., 2019). Oleh sebab itu, hakikat pendidikan karakter dalam konteks pendidikan di Indonesia yakni pendidikan nilai, yakni pendidikan nilai luhur yang bersumber dari budaya bangsa Indonesia sendiri, dalam rangka membentuk pribadi peserta didik yang berkarakter sesuai dengan nilai-nilai luhur bangsa (Bialik et al., 2015).

Strategi sekolah dalam penguatan pendidikan karakter berbasis nilai religius, nasionalisme, gotong royong, kemandirian, dan integritas telah dibagi ke dalam aspek pembelajaran dan non pembelajaran. Keseluruhan bentuk strategi tersebut dibentuk dalam rangka penguatan karakter peserta didik berbasis nilai religius, nasionalisme, gotong royong, kemandirian, dan integritas, strategi yang baik dan terinci dapat mempermudah pihak sekolah dalam mencapai tujuan yang diharapkan ke depan (Botha, 2010; Fahrilyani et al., 2019). Strategi menjadi bagian dari suatu proses perencanaan dan pelaksanaan pendidikan di sekolah (Habibu et al., 2020). Kepala sekolah, guru, dan tenaga kependidikan harus memahami dan bisa menentukan strategi yang tepat dalam upaya mengoptimalkan implementasi penguatan pendidikan karakter di sekolah.

Penerapan pendidikan karakter perlu didukung oleh strategi yang baik. Hal ini berkaitan dengan bagaimana implementasi program pendidikan karakter dapat terlaksana dengan baik. Penerapan program pendidikan karakter perlu mendapat daya dukung dari manajemen sekolah untuk mengatur seperti apa perencanaan, pengkoordinasian, pelaksanaan, dan pengawasan program pendidikan karakter di sekolah (Khoury, 2017; Maisyaroh et al., 2019; Pala, 2011). Adanya manajemen sekolah dalam bentuk program manajemen penguatan pendidikan karakter, membantu kepala sekolah dan guru untuk mengondisikan aspek pendukung pelaksanaan pendidikan karakter itu sendiri seperti sarana, prasarana, sumber belajar, dan pola pembinaan karakter peserta didik melalui kegiatan intrakurikuler, kokulikuler dan ekstrakurikuler (Iswan \& Bahar, 2018; Wahyuni \& Mustadi, 2016).

Strategi penguatan pendidikan karakter peserta didik di SD Laboratorium Universitas Negeri Malang, Kota Blitar, dituangkan ke dalam Rencana Kegiatan dan Anggaran Sekolah (RKAS). Perumusan strategi sekolah tersebut berorientasi visi dan misi sekolah, serta disesuaikan dengan kebutuhan peserta didik. Pendidikan karakter di sekolah dilaksanakan sesuai dengan visi dan misi sekolah termasuk disesuaikan dengan ciri khas pembelajaran sekolah yang berkiblat pada pola pendidikan barat dengan berfokus pada pemahaman dan penggunaan Bahasa Inggris sebagai keunggulan sekolah. Dipadukan dengan adat ketimuran yang dijabarkan dalam kegiatan pembinaan karakter peserta didik. Perencanaan program termasuk proses perumusan strategi penguatan pendidikan karakter peserta didik di SD Laboratorium Universitas Negeri Malang, Kota Blitar dilakukan melalui rapat kerja. Rapat Kerja yang dilakukan oleh sekolah melibatkan berbagai komponen sekolah, mulai dari kepala sekolah, Guru, Tenaga Kependidikan, Orang Tua, Komite Sekolah, Stakeholder, Expert/Ahli Pendidikan, dengan Kepala Sekolah sebagai pengambil keputusan tertinggi. Rapat dilakukan melalui mekanisme musyawarah, yang dilakukan sebelum tahun ajaran baru. Hal tersebut dilakukan guna mencapai tujuan yang telah ditentukan.

Keterlibatan dari pihak-pihak tersebut tentu amat penting guna menunjang keberhasilan program penguatan pendidikan karakter berbasis nilai pancasila di SD Laboratorium Universitas Negeri Malang, Kota Blitar (Jeynes, 2019; Maisyaroh et al., 2020; Saidek et al., 2016). Keefektifan perumusan strategi 
sekolah harus menghasilkan strategi yang luwes dan berpusat pada peserta didik, yang meliputi program pembelajaran, pengembangan kurikuler, sumber daya manusia, kegiatan peserta didik, elaborasi kurikulum menjadi bahan pengajaran, hubungan sekolah dengan masyarakat, laboratorium, gedung sekolah, keuangan sekolah, dan perpustakaan (Bandur, 2012; Botha, 2010; Maisyaroh et al., 2021). Strategi dapat berhasil diimplementasikan dengan baik, jika kepala sekolah memberdayakan seluruh warga sekolah guna bekerja sama dalam usaha mengefektifkan program-program sekolah melalui usaha kolektif bersama warga sekolah guna mencapai tujuan yang sudah ditentukan (Juharyanto et al., 2021; Kamaruddin, 2012; Liçkona et al., 2015).

Pembentukan budaya sekolah berbasis pendidikan karakter dapat dilakukan melalui keteladanan, kegiatan rutin, kegiatan spontan, serta pengkondisian lingkungan sekolah (Berkowitz \& Bier, 2004; Maftei \& Holman, 2019). Kegiatan rutin sekolah merupakan kegiatan yang dilakukan oleh peserta didik secara terus menerus atau konsisten setiap saat (Amini et al., 2017; Hidayati et al., 2014). Beberapa hasil penelitian sebelumnya menunjukkan bahwa salah satu indikator keberhasilan pembentukan karakter berbasis nilai religius, nasionalisme, gotong royong, kemandirian, dan integritas adalah siswa memiliki perilaku yang menunjukkan nilai-nilai tersebut secara melekat, artinya karakter tersebut ditunjukkan dalam perilaku sehari-hari dalam bermasyarakat (Fajar, 2018; Rahayu et al., 2017; Zurqoni et al., 2018). Usaha dalam penguatan karakter peserta didik harus dirumuskan melalui strategi yang tepat oleh sekolah agar kemungkinan keberhasilan pencapaian tujuan dapat dioptimalkan (Diggs \& Akos, 2016; Fahrilyani et al., 2019).

Pendidikan karakter dalam pelaksanaannya di sekolah perlu mendapat dukungan manajemen penguatan pendidikan karakter. Dalam implementasinya sendiri terkadang baik kepala sekolah maupun guru kesulitan dalam memahami maksud dari program pendidikan karakter itu sendiri dan bagaimana mengintegrasikannya kedalam aktivitas pendidikan di sekolah maupun pembelajaran di kelas (Novianti, 2017; Rokhman et al., 2014). Apalagi nilai-nilai yang terkandung dalam program penguatan pendidikan karakter tersebut harus terintegrasi dalam aktivitas pengelolaan maupun pembelajaran di sekolah (Imron \& Nugrahani, 2019; Ismail et al., 2016). Sehingga diperlukan sebuah proses penguatan untuk dapat mengintegrasikan nilai-nilai dalam pendidikan karakter yang telah direncanakan dengan baik sejak awal.

\section{SIMPULAN}

Sekolah Dasar Laboratorium Universitas Negeri Malang menerapkan praktik-praktik inovatif dalam rangka manajemen penguatan pendidikan karakter berdasarkan nilai religius, nasionalisme, gotong royong, kemandirian, dan integritas. Strategi penguatan pendidikan karakter dibagi ke dalam aspek pembelajaran dan non pembelajaran. Pendidikan karakter di sekolah dilaksanakan sesuai dengan visi dan misi sekolah termasuk disesuaikan dengan ciri khas pembelajaran sekolah yang berkiblat pada pola pendidikan barat dengan berfokus pada pemahaman dan penggunaan Bahasa Inggris sebagai keunggulan sekolah. Dipadukan dengan adat ketimuran yang dijabarkan dalam kegiatan pembinaan karakter peserta didik. Dampak dari penerapan strategi sekolah dalam penguatan karakter peserta didik melekat pada keseharian peserta didik baik di lingkungan sekolah maupun di lingkungan tempat tinggalnya dan terus terbawa hingga mereka dewasa.

\section{REFERENCE}

Agboola, A., \& Tsai, K. C. (2012). Bring Character Education into Classroom. European Journal of Educational Research, 1(2), 163-170. https://doi.org/10.12973/eu-jer.1.2.163

Ahmad, S. D. (2018). Finding Indonesian National Leaders Based On Pancasila ' S Character The Member of Indonesian Parliament ( Dewan Perwakilan Rakyat Republik Indonesia ). Journal of Social Sciences and Humanities Invention, 5(09), 4969-4973. https://doi.org/10.18535/ijsshi/v5i9.02

Amini, A., Yurnita, S., \& Hasnidar, H. (2017). The Development of Character Education Model Trough an Integrated Curriculum At Elementary Education Level in Medan City. International Journal on Language, Research and Education Studies, 1(2), 298-311. https://doi.org/10.30575/2017091210 
Amir, S. (2013). Pancasila as Integration Philosophy of Education And National Character. International Journal of Scientific and Technology Research, 2(1), 54-57.

Arifin, I., Juharyanto, Mustiningsih, \& Taufiq, A. (2018). Islamic Crash Course as a Leadership Strategy of School Principals in Strengthening School Organizational Culture. SAGE Open, 8(3), 1-10. https://doi. org/10.1177/2158244018799849

Bandur, A. (2012). School-Based Management Developments: Challenges and Impacts. Journal of Educational Administration, 50(6), 845-873. https://doi.org/10.1108/09578231211264711

Berkowitz, M. W., \& Bier, M. C. (2004). Research Based Character Education. Annals of the American Academy of Political and Social Science, 591(1), 72-85. https://doi.org/10.1177/0002716203260082

Bialik, M., Bogan, M., Fadel, C., \& Horvatova, M. (2015). Character Education for the 21 st Century: What should students learn? Center for Curriculum Redesign.

Botha, R. J. (2010). School effectiveness: Conceptualising divergent assessment approaches. South African Journal of Education, 30(4), 605-620. https://doi.org/10.15700/saje.v30n4a391

Dennis, M., \& Harrison, T. (2020). Unique Ethical Challenges for the 21st Century: Online Technology and Virtue Education. Journal of Moral Education, 1-16. https://doi.org/10.1080/03057240.2020.1781071

Diggs, C., \& Akos, P. (2016). The Promise of Character Education in Middle School: A Meta-Analysis. Middle Grades Review, 2(2), 1-19.

Djiwandono, P. I. (2016). Character Education in Content Courses: Self-Scoring As a Means for Developing Honesty in Students. TEFLIN Journal, 27(2), 153-165. https://doi.org/10.15639/teflinjournal.v27i2/153-165

Fahrilyani, D., Maisyaroh, \& Kusumaningrum, D. E. (2019). Manajemen Pembinaan Karakter Peserta Didik Di Sekolah Dasar. Jurnal Administrasi Dan Manajemen Pendidikan, 2(4), 204-212. https://oi.org/10.17977/ um027v2i42019p204

Fajar, A. (2018). Prevention of Corruption through Anti-Corruption Education. Advances in Social Science, Education and Humanities Research, 251(Acec), 650-653. https://doi.org/https://dx.doi.org/10.2991/acec18.2018.145

Habibu, P. S., Wondal, R., \& Alhadad, B. (2020). Kajian Strategi Implementasi Pendidikan Karakter Anak Usia Dini. Jurnal Pendidikan Anak Usia Dini, 3(1), 117-127.

Hidayati, A., Zaim, M., Rukun, K., \& Darmansyah. (2014). The Development of Character Education Curriculum for Elementary Student in West Sumatera. International Journal of Educational Research, 2(6), 189-198.

Imron, A. A. M., \& Nugrahani, F. (2019). Strengthening Pluralism in Literature Learning for Character Education of School Students. Humanities and Social Sciences Reviews, 7(3), 207-213. https://oi.org/10.18510/ hssr.2019.7332

Ismail, Thalib, S. B., Samad, S., \& Mahmud, R. (2016). The Development of Character Education Model to Improve Students' Academic Independence in Islamic Boarding School in Sinjai District, Indonesia. New Educational Review, 46(4), 29-39. https://doi.org/10.15804/tner.2016.46.4.02

Iswan, \& Bahar, H. (2018). Penguatan Pendidikan Karakter Perspektif Islam dalam Era Millenial IR. 4.0. Seminar Nasional Pendidikan Era Revolusi "Membangun Sinergitas Dalam Penguatan Pendidikan Karakter Pada Era IR 4.0".

Izfanna, D., \& Hisyam, N. A. (2012). A Comprehensive Approach in Developing Akhlaq: A Case Study on the Implementation of Character Education at Pondok Pesantren Darunnajah. Multicultural Education and Technology Journal, 6(2), 77-86. https://doi.org/10.1108/17504971211236254

Jeynes, W. H. (2019). A Meta-Analysis on the Relationship Between Character Education and Student Achievement and Behavioral Outcomes. Education and Urban Society, 51(1), 33-71. https://doi. org/10.1177/0013124517747681

Jianfei, H. U., Xiuyun, W., Di, W., \& Chaoqian, T. (2017). The Influence and Enlightenment of the Media on National Spirit. Canadian Social Science, 13(8), 13-18. https://doi.org/10.3968/9843

Juharyanto, Arifin, I., Sultoni, \& Adha, M. A. (2021). Dominance One-Roof Schools Principal Excellent Leadership in the Digital Age in Indonesia. Eurasian Journal of Educational Research, 21(93), 199-218. https://doi. org/10.14689/ejer.2021.93.10

Juharyanto, Bafadal, I., Arifin, I., Saputra, B. R., \& Adha, M. A. (2020). The Use of Conventional Communication Technology as an Effective Principal Leadership Strategy in Strengthening the Role of Multi-Stakeholder's Forum for School Quality Improvement. Elementary Education Online, 19(4), 1963-1973. https://doi. org/10.17051/ilkonline.2020.762773

Kamaruddin, S. A. (2012). Character Education and Students Social Behavior. Journal of Education and Learning, 6(4), 223-230. https://doi.org/10.11591/edulearn.v6i4.166 
Khoury, R. (2017). Character Education as a Bridge from Elementary to Middle School: A Case Study of Effective Practices and Processes. International Journal of Teacher Leadership, 8(2), 49-67.

Krettenauer, T. (2020a). Moral Identity as a Goal of Moral Action: A Self-Determination Theory Perspective. Journal of Moral Education, 49(3), 330-345. https://doi.org/10.1080/03057240.2019.1698414

Krettenauer, T. (2020b). Moral Sciences and the Role of Education. Journal of Moral Education, 1-15. https://doi. org/10.1080/03057240.2020.1784713

Liçkona, T., Schaps, E., \& Lewis, C. (2015). Eleven Principles of Effective Character Education. The Character Education Partnership. https://www.educationalimpact.com/resources/TeachChar/pdf/eleven_principles.pdf

Maftei, A., \& Holman, A. (2019). Representation of Morality in Children: A Qualitative Approach. Journal of Moral Education, 49(2), 194-208. https://doi.org/10.1080/03057240.2019.1619542

Maisyaroh, Juharyanto, Bafadal, I., Wiyono, B. B., Adha, M. A., Saputra, B. R., \& Ariyanti, N. S. (2020). Implementation of Principal Instructional Leadership in Facilitating Learning Independency Policy on 4 . 0 Industrial Era Orientation in Indonesia. Proceedings of the 2nd Early Childhood and Primary Childhood Education (ECPE 2020) Implementation, 487(Ecpe), 206-211. https://doi.org/https://dx.doi.org/10.2991/ assehr.k.201112.037

Maisyaroh, Juharyanto, Bafadal, I., Wiyono, B. B., Ariyanti, N. S., Adha, M. A., \& Qureshi, M. I. (2021). The Principals' Efforts in Facilitating the Freedom to Learn by Enhancing Community Participation in Indonesia. Cakrawala Pendidikan, 40(1), 196-207. https://doi.org/https://doi.org/10.21831/cp.v40i1.36119

Maisyaroh, Mustiningsih, Kusumaningrum, D. E., \& Nasih, A. M. (2019). Development of the Model of Implementation and Evaluation of the 21st Century Community Participation in the Pesantren-Based Junior High School. International Journal of Innovation, Creativity and Change, 5(4sp), 599-610. https://doi. org/10.2991/icet-19.2019.144

Miles, M. B., Huberman, A. M., \& Saldana, J. (2014). Qualitative Data Analysis. Sage.

Muassomah, Abdullah, I., Istiadah, Mujahidin, A., Masnawi, N., \& Sohrah. (2020). Believe in Literature: Character Education for Indonesia's Youth. Universal Journal of Educational Research, 8(6), 2223-2231. https://doi. org/10.13189/ujer.2020.080605

Novianti, N. (2017). Teaching Character Education to College Students Using Bildungsromans. International Journal of Instruction, 10(4), 255-272. https://doi.org/10.12973/iji.2017.10415a

Pala, A. (2011). The Need for Character Education. International Journal of Social Sciences and Humanity Studies, $3(2), 23-32$.

Parker, L., \& Raihani, R. (2011). Democratizing Indonesia through Education? Community Participation in Islamic Schooling. Educational Management Administration \& Leadership, 39(6), 712-732. https://doi. org/10.1177/1741143211416389

Peraturan Menteri Pendidikan dan Kebudayaan Nomor 20 Tahun 2018 Tentang Penguatan Pendidikan Karakter Pada Satuan Pendidikan Formal.

Rahayu, E. S., Akbar, S., \& Murtiningsih. (2017). An Implementation of Character Education for Character Education in Elementary Schools. Journal of Social Sciences, 6(3), 504-517. https://doi.org/10.25255/ jss.2017.6.3.504.517

Raihani. (2011). A Whole-School Approach: A Proposal for Education for Tolerance in Indonesia. Theory and Research in Education, 9(1), 23-39. https://doi.org/10.1177/1477878510394806

Rokhman, F., Hum, M., Syaifudin, A., \& Yuliati. (2014). Character Education for Golden Generation 2045 (National Character Building for Indonesian Golden Years). Procedia - Social and Behavioral Sciences, 141, 1161-1165. https://doi.org/10.1016/j.sbspro.2014.05.197

Saidek, A. R., Raisul Islami, \& Abdoludin. (2016). Character Issues: Reality Character Problems and Solutions through Education in Indonesia. Journal of Education and Practice, 7(17), 158-165.

Sukadari, Sukemi, B. M., \& Sunarti. (2019). Local Socio-Cultural Wisdom as a Basis of Character Education in Primary Schools. International Journal of Innovation, Creativity and Change, 7(6), 298-311.

Wahyuni, M., \& Mustadi, A. (2016). Pengembangan Perangkat Pembelajaran Collaborative Learning Berbasis Kearifan Lokal Untuk Meningkatkan Karakter Kreatif Dan Bersahabat. Jurnal Pendidikan Karakter, 6(2), 246-260. https://doi.org/p-ISSN:2089-5003

Zurqoni, Retnawati, H., Apino, E., \& Anazifa, R. D. (2018). Impact of Character Education Implementation: A Goal-Free Evaluation. Problems of Education in the 21st Century, 76(6), 2018. https://doi.org/10.33225/ pec/18.76.881 